\title{
Universiteit
}

Leiden

The Netherlands

\section{Added value of elder abuse definitions: a review}

Mysyuka, Yuliya; Westendorp, Rudi G.J.; Lindenberg, Jolanda

\section{Citation}

Mysyuka, Y., Westendorp, R. G. J., \& Lindenberg, J. (2012). Added value of elder abuse definitions: a review. Retrieved from https://hdl.handle.net/1887/46805

Version: $\quad$ Not Applicable (or Unknown)

License: $\quad$ Leiden University Non-exclusive license

Downloaded from: https://hdl.handle.net/1887/46805

Note: To cite this publication please use the final published version (if applicable). 
Review

\title{
Added value of elder abuse definitions: A review
}

\author{
Yuliya Mysyuk $^{\mathrm{a}, *}$, Rudi G.J. Westendorp ${ }^{\mathrm{a}, \mathrm{b}}$, Jolanda Lindenberg ${ }^{\mathrm{a}}$ \\ a Leyden Academy on Vitality and Ageing, Poortgebouw LUMC, Rijnsburgerweg 10, 2333 AA Leiden, The Netherlands \\ ${ }^{\mathrm{b}}$ Leiden University Medical Center, PO Box 9600, 2300 RC Leiden, The Netherlands
}

\section{A R T I C L E I N F O}

\section{Article history:}

Received 2 January 2012

Received in revised form 28 March 2012

Accepted 3 April 2012

Available online 25 April 2012

\section{Keywords:}

Elder abuse

Definition

Purpose

\begin{abstract}
A B S T R A C T
Elder abuse has devastating consequences for older persons such as a poor quality of life, psychological distress, and loss of property and security. It is also associated with increased mortality and morbidity. Elder abuse is a problem that manifests itself in both rich and poor countries and at all levels of society. It is timely to discuss one of the basic problems that has hampered the study, detection and intervention of elder abuse as the variety of definitions that exist now produce a definitional chaos for researchers, practitioners, and policy makers.

In this article we trace the elements of "how to define elder abuse" and situate them in their socio-historical context. We also analyze the purposes of these different definitions to assess their appropriateness in different settings concerned with elder abuse. Our analysis shows that elder abuse mirrors the societal arrangements which gave rise to them. It also highlights that it is a complex problem that is difficult to define. The central question is whether we need a common definition of elder abuse or different definitions that can be used in different settings. By evidence of our analysis we can see that there is a need for a sufficiently broad and flexible definition in order to cover different behaviors that can constitute abuse and the various settings in which it may occur. On the other hand, the definition needs to be specific and concrete to be useful in professional contexts.

To take a further step forward for both research and practice of elder abuse, we propose to consistently adhere to the WHO definition that leads the enquirer towards a better understanding of the problem and helps to distinguish it from other phenomena; and to a simplified definition for professional practice that sets boundaries to the phenomena and is appropriate for effective prevention and intervention measures.
\end{abstract}

() 2012 Elsevier B.V. All rights reserved.

\section{Introduction}

Elder abuse remained hidden and taboo until quite recently. After child abuse and domestic violence were discussed publicly in the 1970s, elder abuse emerged as a form of family violence. During the early 1980s more public and professional interest was given to the issue of elder abuse (McCreadie, 1996, 2003; Pritchard, 1995). What exactly constituted elder abuse, however, was at that time less at the center of attention. Despite the fact that the problem of elder abuse has gained more public attention and quite some research was conducted, global statistics are still lacking, in many instances health care professionals still ignore it, and even now not enough action is taken to protect the individuals subjected to abuse. Moreover cases are often not recorded and unreported (Perel-Levin, 2008). Part of this underreporting is due to the complexity of and unequivocality inherent in the phenomenon itself: abuse can take place in a whole range of settings, including

\footnotetext{
* Corresponding author. Tel.: +31 715240968.

E-mail address: mysyuk@leydenacademy.nl (Y. Mysyuk).
}

hospitals, nursing homes, residential care homes, day centers and even the person's own home, perhaps the one place where the older person might feel safest (Abbey, 2009; Ansello and O'Neill, 2010; Arai, 2006). Family members, adult children, or spouses are implicated in $90 \%$ of the cases of elder abuse. Other abusers include care professionals such as health or social workers, friends, or neighbors. Sometimes the abusers do not recognize what they are doing as a form of abuse; they, and at times their victims, do not know what constitutes abuse and what not, different organizations and professionals still use different terminology, adhere to different definitions and thus perceive abuse differently. This causes significant issues for research as it makes it more difficult to compare the outcomes of various reports as the result of the inconsistencies in the definitions of elder abuse (Pillemer and Wolf, 1986; Pillemer and Prescott, 1989; Newton, 2010).

Lack of agreement about the definition and its parameters has made the assessment of prevalence and incidence problematic from an empirical perspective (Harbison and Morrow, 1998). It makes it especially difficult to determine the extent of the problem of elder abuse. Prevalence rates of elder abuse of between 4 and $6 \%$ were found in Canada, Great Britain, Finland and a 
prevalence rate of between one and ten percent was estimated in the USA (Griffin, 1994; Pillemer and Finkelhor, 1988). In the Netherlands one prevalence study on elder abuse showed a $5.6 \%$ prevalence rate (Comijs et al., 1998, 2000; Comijs, 1999). Inadequate knowledge and training in how to detect abuse and a lack of staff awareness of what constitutes abuse can lead to underreporting of cases of abuse, underestimation and imprecise prevalence rates (Anetzberger, 2004; Griffin, 1994; Kivela et al., 1992; Ogg and Bennett, 1992; Podnieks, 1992). Some prevalence studies include only one form of elder abuse, such as solely physical abuse and others more than one, for example, physical and psychological abuse. As a result, prevalence rates are inconsistent and incomparable. On top of this, the studies involved provide different interpretations of elder abuse, this makes it confusing to analyze and understand the phenomenon in a comparative way and it also has an impact on further research, and thus for the development of policies, prevention and intervention programmes.

As a first step towards further developing the field of elder abuse in a comparative way, this article reviews definitions of elder abuse taking into account different aspects of these definitions and effects they can have on research and professional practice. The purpose of this analysis is to come to an understanding of the development of research and practice in elder abuse. By enabling comparative understanding it hopes to contribute to a comprehensive approach towards elder abuse.

\section{Methods}

\subsection{Identification of studies}

Studies were identified by searches of 11 databases (PsycINFO, PubMed, EMBASE, Web of Science, CINAHL, Academic Search Premier, ScienceDirect, Wiley, LWW, HighWire, Taylor\&Francis/Informa). The search strategy consisted of the AND combination of two concepts: "elder abuse", "definitions". For these concepts, all relevant keyword variations were used; not only keyword variations in the controlled vocabularies of the various databases; but the free text word variations of these concepts as well (such as: elder neglect; elder mistreatment; terminology; concepts; ontologies). Searches were restricted to papers published in English. The bibliographies of relevant original and review articles were screened aimed to include all published studies that provide information about the phenomenon of elder abuse; definitions of elder abuse; problems in defining elder abuse; the development of definitions; comparison and analysis of different definitions. The titles and abstracts of all articles identified by the search were screened and potentially relevant articles were retrieved and assessed. Additional relevant articles were identified through Pubmed; Google Scholar and other relevant search engines. Relevant books and chapters of the books were also included to the review.

\subsection{Inclusion and exclusion criteria}

The studies which provided information about the phenomenon of elder abuse, definitions of elder abuse, problems in defining elder abuse, the development of definitions, comparison and analysis of different definitions or any information were included in the review.

The articles that did not contain necessary and relevant information were excluded from the review.

\subsection{Results of the search}

The PsycINFO yielded 113 hits, the PubMed yielded 77 hits from which 52 were unique (not found in other databases), the MEDLINE yielded 80 hits ( 0 unique), the Embase yielded 35 (12 unique), the Web of Science yielded 56 hits (17 unique), the CINAHL yielded 84 hits (36 unique), the Academic Search Premier yielded 42 hits (0 unique), the ScienceDirect yielded 4 hits (1 unique), the WileyBlackwell yielded 12 hits ( 0 unique), the LWW yielded 96 hits (76 unique), the Taylor\&Francis yielded 38 hits (19 unique) and the COCHRANE yielded 0 hits.

Screening of titles and abstracts identified potentially relevant papers; then the papers was thoroughly studied and 12 studies which met the inclusion criteria are addressed in this review.

Other relevant studies which were identified from reference lists, authors and additional search engines were also included in the review (see Fig. 1).

Information obtained during the symposium "Elder abuse in context" (Leiden, 2011), interviews, exchanges and meetings with professionals, experts, older people also contributed to this review.

\subsection{Classification of definitions}

To explore definitions of elder abuse, we will first discuss what kinds of definitions are commonly distinguished and which purposes they serve, as a comparative starting point for our analysis of elder abuse definitions. This will be the first starting point for our analytical framework for these definitions.

In a long history of definitions, many strands have become tangled together, so that "definition" has implicitly come to mean many different things to many people, often in ways that are inconsistent (Cregan, 2005). As a first step, Robinson (1950) distinguished two types of definitions: lexical (or also dictionary) and stipulative.

Lexical definitions are used when we need to explain the existing meaning of an old word or term; that is, a word/term that is already in use in the community, but unfamiliar to the person wanting the explanation. Lexical definitions seek to pinpoint what was meant by some word to someone at some point in time (Belnap, 1993).

If one might wish to explain a proposed meaning for a new word, stipulative definitions will be used. The purpose is to specify that a certain term will be used only to mean a certain precise thing within a given context (Belnap, 1993; Ierodiakonou, 1993). This may be a broadening or narrowing of an existing sense of a term; a completely new usage of an existing term; or may involve the creation of a totally new term. It is a specification of how the author intends to use the term in the future within a particular work or context, and binds the author to making good on that intention (Zalta et al., 2009).

However, besides the two types that Robinson (Gulpa, 2008) distinguished, there are also many cases not exhibiting either one of these types, including perhaps most distinctively philosophical definitions; in these cases one wants both to rely on an old, existing meaning and to attach a new, proposed meaning, they try to explain the circumstances of elder abuse without necessarily being a full sum-up of the conditions that make it count as elder abuse. For this purpose a third type of definition, here called explicatory, is used in which analyses or explications expounded.

The three broadly distinguished types of definitions - lexical, stipulative and explicatory - discussed above can be identified in definitions of elder abuse as well. These types will be used as a conceptual framework to analyze elder abuse definitions in this review.

The incongruity between different interpretations and definitions of elder abuse also has their impact on the understanding of the consequences of the phenomenon. To explain the impact of elder abuse, we need to have a clear idea of what that phenomenon entails. Clear definitions serve several important purposes: 


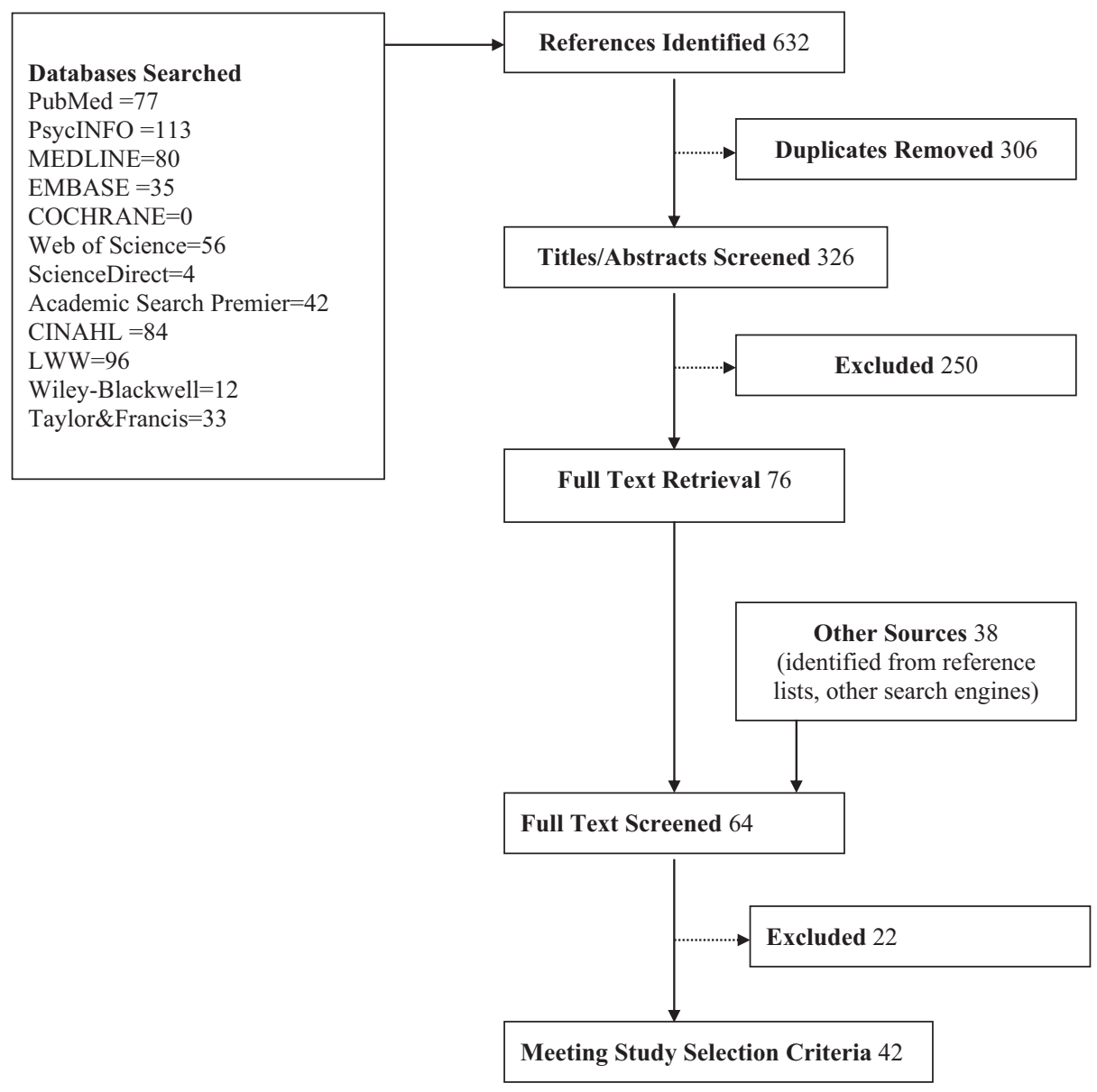

Fig. 1. Literature search results flow chart.

- As pointers towards the social problem in question which guide towards a clearer understanding of the issue.

- Definitions help to focus on the social problem under study and differentiate it from other phenomena.

- Clear and consistent definitions are necessary for permitting effective intervention and prevention strategies (Biggs et al., 1995).

The three purposes can be identified in elder abuse definitions as well and that is the second tool in our analysis of elder abuse definitions. The overview of our analytical framework comprising the different types of definitions and the purposes that they serve is shown in Table 1.

Table 1

Types of definitions and their purposes.

\begin{tabular}{|c|c|c|}
\hline $\begin{array}{l}\text { Type of } \\
\text { definition }\end{array}$ & Semantics & Purpose \\
\hline Lexical & $\begin{array}{l}\text { Existing meaning of an old } \\
\text { word/term }\end{array}$ & $\begin{array}{l}\text { Better understanding of } \\
\text { phenomenon; focus on the } \\
\text { problem under study }\end{array}$ \\
\hline Stipulative & $\begin{array}{l}\text { Proposed meaning for a new } \\
\text { word }\end{array}$ & $\begin{array}{l}\text { Effective prevention and } \\
\text { intervention strategies }\end{array}$ \\
\hline Explicatory & $\begin{array}{l}\text { Both existing and proposed } \\
\text { meaning }\end{array}$ & $\begin{array}{l}\text { Better understanding of } \\
\text { phenomenon, explaining casual } \\
\text { mechanisms }\end{array}$ \\
\hline
\end{tabular}

\section{Results}

\subsection{The development of elder abuse definitions}

Despite that the recognition of elder abuse provoked quite a lot of debate, there was little attempt to place the phenomenon in some form of conceptual framework for some time. There is no common vision on definitions of elder abuse. In this article the evolvement of definitions of elder abuse in historical perspective will be analyzed. A critical analysis is insightful because it can enlighten our understanding in elder abuse and enable a step-forward in the conceptualization and understanding of the problem.

The definitions of elder abuse changed and developed considerably over time: from "granny battering", "granny bashing" to "elder mistreatment" and "elder abuse" (1970-2000s). Some of them were rather similar and had shared intentions, other ones introduced new and different elements. An overview can be found in Fig. 2.

\subsection{Females and physical assault}

In the 1970s the focus of early definitions of elder abuse was on physical assault of older women with the use of the terms "granny battering", "granny bashing" and "granny battering syndrome". Part of the explanation for the attention for elder abuse at that exact point in time can be linked to larger developments in society. The Industrial Revolution set the stage for reshaping the status older persons occupy in our society and their associated values. Through 


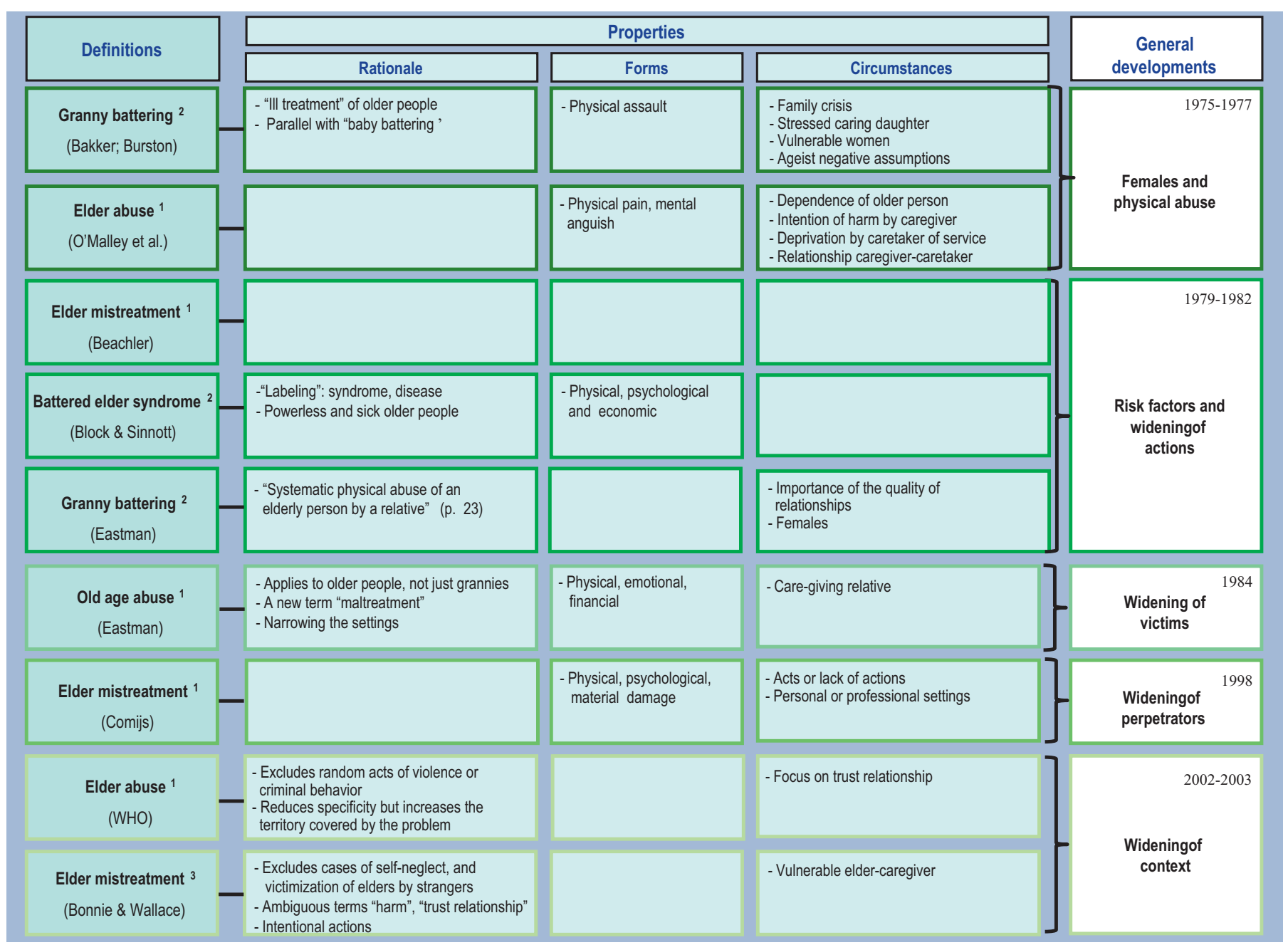

Fig. 2. Development of elder abuse definitions, ${ }^{1}$ lexical ${ }^{2}$ stipulative, ${ }^{3}$ combination.

this revolution, men generally gained position in the upper tiers of societal hierarchy, predominantly controlling decision-making and resources. Having power to control resources put them into visible roles in society, maintaining the status quo. Those individuals lacking power and visibility, such as women and children, were less valued. This was reflected in the social movement of feminism that developed in response. The attention for females (weak, powerless, vulnerable) in definitions of elder abuse can be seen as mirroring these developments. At the same time we can identify an ongoing, increased incidence rate of abuse, not only of women and children, but also of the elderly (with the special accent on elderly women) generally considered the most invisible and least valued of all (Baron and Welty, 1996). The term "granny battering" was used in the UK as an euphemism for the ill-treatment of older people (Baker, 1975). The terminology of child abuse was adopted, and doctors concerned with the elderly saw "baby battering" to have its parallels for their older patients (Burston, 1975). In Baker's (1975) article, the term included the risks to older people's health and well-being, as well as overmedication and general misuse of drugs, and physical abuse. The "granny battering syndrome" was quickly adopted as a model for social and health care workers, featuring a stressed or burnt-out daughter caring for her physically disabled and slightly confused mother (Eastman, 1982; Cloke, 1983; Schlesinger, 1984).

Besides the focus on vulnerable females, another focus that can be identified in these definitions was the one on physical assault.
Case examples were cited to suggest that those at risk were living in three generations families: "the domestic situation may well be linked to a pressure cooker" (Burston, 1977). The term "granny battering" itself revealed the often ageist assumptions that lay behind its labeling, where elderly victims are seen as passive recipients of care and therefore a burden to their family.

In a later definition of elder abuse by O'Malley et al. (1979, p. 13) attention was again given to physical abuse. They defined it as: "the willful infliction of physical pain, injury or debilitating mental anguish, unreasonable confinement or deprivation by a caretaker of services which are necessary to the maintenance of mental and physical health". This definition broadened the context of physical abuse in comparison to previous definitions. The abuse was also considered as intention of harm. The relationship between caregiver and caretaker was introduced. In spite of these new elements, this definition still describes elder abuse quite narrowly; the terminology used in the definition is difficult, and not fully unambiguous. It can be considered a lexical definition; elements require definition by themselves. It applies the label of abuse only if there is the relationship "caregiver"-"care-receiver/caretaker" and when the caregiver intends to do harm. It also assumes that the older person is dependent. This assumption effectively excludes independent elderly who, as we know from prevalence studies (Griffin, 1994; Pillemer and Finkelhor, 1988; Anetzberger, 2004; Griffin, 1994; Kivela et al., 1992; Ogg and Bennett, 1992; Podnieks, 1992), may also be the victim of abuse. 
In the early definitions of elder abuse one can thus observe similar elements. The emphasis of these definitions was on vulnerable and unprotected women who were dependent on other people and elder abuse was only associated with physical battering. These definitions were also more clinically oriented.

\subsection{Risk factors and widening of actions}

The focus of later elder abuse definitions shifted to risk factors and different types of abuse. For example, Beachler in his definition of "elder mistreatment (McMullen, 2004)", focused on risk factors of abuse such as: dependency, developmental disorder of abuser, situational crisis of abuser, or victim and long-term environmental conditions). Beachler tried to determine the underlying associated factors of elder mistreatment and what actions should be taken. His work was never published, but it reflected the tendency of that period; it was focused on more than just physical assault and moved away from the term 'battering' that denotes a physical emphasis. Elder abuse was put in a wider context. Thus changes in the tendencies in society such as reshaping the status of older persons and their values, maintaining status quo of men, social movement of feminism were reflected in the definitions of elder abuse.

Around the same time another definition appeared; the "battered elder syndrome" (Block and Sinnott, 1979). The battered elder syndrome included types of abuse instead of the incorporation of risk factors as Beachler for instance had done. Three major categories of abuse were distinguished: physical, psychological, and financial. Physical abuse included both bruises as well as lack of supervision and proper care that can lead to injuries. In the category of psychological abuse, threats and isolation were included. Stealing or cheating the elderly out of their own funds and possessions constituted material or economic abuse. Abuse was further defined in terms of verbal and emotional factors (Block and Sinnott, 1979). It was a step forward in defining elder abuse as forms of abuse were distinguished more clearly and it went beyond physical abuse, although "battered" still connoted physical abuse. In spite of this fact, the term "battered elder syndrome" is kind of a label that has a definite physical association. It seemed from this definition that abuse is a disease and it needed treatment and older people are those who were seen as patients; powerless and sick. As the early definitions of elder abuse this definition also focused on unable, sick, susceptible elderly.

Mervyn Eastman, a practicing social worker from London in a similar trend, defined "granny battering" as "the systematic physical abuse of an elderly person by a relative" (p. 8). Eastman pointed out that ageist attitudes could result in a denial by professionals that physical abuse existed. The problem of abuse was conceptualized in terms of care-giving and emphasis was again put on the dependency and vulnerability of the older person, arising from their physical and mental frailty and on the stress entailed in caring. By implication, the key persons in this situation, both older person and caring relative, were females following the still prevalent tendency of that time (McCreadie, 1993).

Two years later Eastman (1982) widened his definition: "granny battering is defined in general terms as the abuse, either physical, emotional or psychological of the elderly by a care-giving relative on whom that elderly person is dependent" (Eastman, 1982). The types of abuse that were mentioned were physical assault, neglect, financial exploitation and abandonment of an older person by a relative. He later added sexual abuse to this list (McCreadie, 1993). This definition widened the context of abuse, showed it in a different, and wider perspective, a similar tendency as we have observed in Block and Sinnott (1979). The importance of the quality of relationships was emphasized, while stressing that the relationship was one between the elderly and their caregiver. Moreover the addition of the word "systematic" added an emphasis on the continuity of this relationship (Eastman, 1982). A new accent in the definitions of elder abuse was given to victims; assuming that the victims of elder abuse could be all older people thereby changing the widespread belief that older females ("grannies") are the only possible victims of abuse. Eastman's definition of "old age abuse" is a good illustration of this new shift.

\subsection{Widening of victims}

Two years later, Eastman defined old age abuse as "the systematic maltreatment, physical, emotional or financial, of an elderly person by a care-giving relative" (Eastman, 1984, p. 23). Eastman pointed out that terms such as "granny battering" and "granny bashing" were unsatisfactory since "battering" and "bashing" are suggestive of the actions of hooligans and thugs, while "granny" is expressing sweet innocence. Therefore the term "old age abuse" makes clear that abuse applies to older people, not just "grannies" showing heterogeneity within the older group. It also suggested a link with the concept "child abuse" placing elder abuse firmly within the family context (Eastman, 1984). Two things about this definition can further be noted: firstly, that systematic maltreatment was introduced as a criterion of abuse and secondly, that care-giving was considered an intrinsic part of the phenomenon, thus limiting elder abuse only to a care-giving situation. Although the strength of this definition is that different types of abuse were again highlighted, at the same time it limits the scope for what counts as abuse and who can be involved. Eastman also mentioned that it was difficult to define precisely what emotional, financial or physical abuse was, because of the different ways people live and deal with things. This was an important point as the complexity of the phenomenon was pointed out and possibilities for further research were opened. This thus brought new views in comparison with his other definitions. Despite of its positive aspects, this definition introduced a new term "maltreatment" which also needed further conceptualization. It also narrowed the settings in which elder abuse can occur to a family setting and by a care-giving relative.

\subsection{Widening of perpetrators}

The continuous widening of the circumstances under which a certain action can be considered elder abuse persisted in the definitions that followed in the 1990s. An example can be Comijs et al. (1998, p. 11) proposed definition of elder mistreatment; "all acts or the refraining from acts towards persons over 65 years of age, by those who have a personal or professional relationship with the older person, leading to (repeated) physical, psychological, and/or material damage". Her definition sets the boundary for being an elderly at 65 years. On the one hand this can be seen as an advantage since a cut-off point for defining an older person was introduced, but on the other hand, it can also be a limitation since people who are under 65 that have experienced abuse due to age-related processes will be excluded in this definition. Defining elder abuse by stipulating a chronological age can have consequences for who counts, and who does not count. While the definition of Comijs is somewhat arbitrary, it is based on the age at which one can begin to receive pension benefits in the Netherlands.

Some developed countries have accepted the chronological age of 65 years (the entitlement age for pension benefits in a number of countries) as a definition of "elderly" or "older" person, but this, for example, does not adapt well to the situation in Africa. Although there are commonly used definitions of old age, there is no general agreement on the age at which a person becomes old and it is questionable whether in practice a chronological age is suitable in this context. The common use of chronological age to mark the threshold of old age assumes equivalence with biological age, yet at the 
same time, it is widely accepted that these two are not necessarily synonymous (Thane, 1978; WHO, 2002, 2011). It shows that there are also problems with defining "older/elderly person" that should be addressed when defining elder abuse comprehensively.

Besides the inclusion of a threshold in chronological age, Comijs also widened her definition in several ways. Abuse could occur in personal or professional settings, forms of abuse were distinguished and it was pointed out that abuse can be "repeated". Therefore, in line with definitions in that period, it broadened the possible situations and included the frequency of behavior as a condition for elder abuse.

\subsection{Widening of context}

The definition of Comijs resembles the definition of the WHO, which is probably the most well-known and widely used currently. The WHO definition can be considered a lexical and explanatory definition: "Elder abuse is a single or repeated act or lack of appropriate action, occurring within any relationship where there is an expectation of trust which causes harm or distress to an older person" (WHO, 2002). It is important to note that elder abuse in this definition, as with Comijs' her definition, excludes random acts of violence or criminal behavior against older people. The harm of elder abuse overlaps with, but is not necessarily synonymous with, criminal acts. A trusting relationship between the abused and the abuser - such as partners, children, in-laws, grandchildren, nurses, social workers and home helps - is at the heart of the issue. In this definition elder abuse is seen as a betrayal of trust. This new focus on trust is derived from the occurrence of elder abuse within different kinds of relationship. Rather than detailing different forms of abuse, the definition cites "single or repeated acts" and "lack of appropriate action". As with "any relationship", each reduces specificity, but widens the context covered by the problem (Brammer and Biggs, 1998). It enables a wider range of inclusion and therefore runs a lower risk of unnecessary exclusion but simultaneously increases the chance of 'false-positives'.

The Panel to Review Risk and Prevalence of Elder Abuse and Neglect in the USA (National Research Council, 2003) developed a definition of elder mistreatment which included a number of conditions we identified in the two last definitions: (a) intentional actions that cause harm or create a serious risk of harm, whether or not intended, to a vulnerable elder by a caregiver or other person who stands in a trust relationship to the elder; (b) failure by a caregiver to satisfy the elder's basic needs or to protect the elder from harm. "Mistreatment" here conveys two ideas: that some injury, deprivation or dangerous condition has occurred to the elder person and that someone else bears responsibility for causing the condition or failing to prevent it (National Research Council, 2003). Two features of this definition merit emphasis. First, the term "mistreatment" was meant to exclude cases of self-neglect. Self-neglect was seen as a separate domain of elder protection, not as a component of mistreatment. Second, elder mistreatment, as defined by the panel, excluded victimization of elders by strangers, as this was seen as a kind of criminal behavior, not as a component of the domain of elder mistreatment that also signals the integration of elder abuse in the field of family violence. The definition of the Panel is an example of a combination of lexical and stipulative definitions. As in the definitions of Comijs and the WHO the stress in this definition was put on the nature of the relationship between the older person and the perpetrator. This definition shows some more striking similarities and differences with the definition of the WHO. As the WHO definition it also focuses on a trust relationship, harm, it also brings attention to intentional actions that can cause harm to an older person. On the other hand, this definition introduced more ambiguous terms than it gave demarcating explanations. Concepts as "elder", "vulnerable elder", "trust relationship", “caregiver", "harm” were mentioned, thus, they also needed to be defined. This made it more complicated, but at the same time it is more comprehensive and fitting to reality because elder abuse is a complex phenomenon involving many variables and it is not easy to define it in a simple way.

\section{Discussion}

Currently the definitions of elder abuse that are widely used are those developed by WHO, the Panel to Review Risk and Prevalence of Elder Abuse and Neglect, and in the Netherlands the definition developed by Comijs. Some of them are old definitions that were modified and others are new ones that were developed lately, reflecting developments and changes in the society.

We can identify from this overview that stipulative definitions, i.e., which explain existing meaning of an old word/term, are usually used in a professional context such as the starting definitions of Eastman, as they need to be concrete and specific. These kinds of definitions enable the observation of elder abuse under specific conditions, by summing up different characteristics. They are useful for this context because they help to indicate the problem clearly and analyze it more precisely, taking into account special features of the particular setting. They also enable specific prevention and intervention on the given conditions.

For research purposes however lexical definitions, i.e., which explain proposed meaning for a new word, are more often applied as they can lead the way towards understanding and explaining the phenomenon without setting too many limiting conditions that would lead to "missing values".

It appears from this review that pure explicatory definitions, i.e., which explain both existing and proposed meaning, are not common in elder abuse definitions. This could be related to the position that the field of elder abuse has within the scientific community, only limited attention is paid to it. As a result there is still a lack of understanding in numerous issue related to elder abuse. It is therefore explainable why this type of definitions is as of yet not really present.

A continuous shift in a wider focus can be found in this overview of definitions. The focus of early definitions was on physical assault and vulnerable and unprotected older women. Later the focus shifted to the forms of elder abuse and abuse applied to all older people, not only females. The context of elder abuse definitions also changed (trust relationship, different settings), and new tendencies appeared. These shifting definitions reflect the socio-historical developments at the time and similarly mirror developments in the field of elder abuse.

It was shown in this review that purposes of definitions, as identified in the first part of this review, are often mixed in elder abuse and that this mixture goes together with the combination of kinds of definitions. However, whether lexical, stipulative or explicatory, it is important to realize that the content of definitions of elder abuse has its implications for research and practice and as a result impacts people's lives directly.

It is crucial to recognize that elder abuse is a very complex issue with diverse definitions and terms. A variety of definitions including use of the interchangeable conceived terms such as "abuse" and "mistreatment" produce a definitional chaos for researchers, policymakers and practicing professionals. Many researchers might have underestimated the problem of elder abuse because they fail to define or operationalize the terms in a clear and objective way. Moreover comparative efforts face difficulties as they might be discussing from a different starting point. It makes it not easy to deal with the problem of elder abuse, differentiate it from other phenomena, to implement intervention and prevention strategies; 
it can provoke difficulty in analyzing the results from previous studies on elder abuse and the development of research and effective policy are frustrated.

On the one hand, we can conclude from this overview that there is a need for a sufficiently broad definition in order to cover different behaviors that can constitute abuse and the setting in which it may occur, to provide improved legal protection, and to develop appropriate multi-disciplinary responses. Such kinds of definitions may be useful and appropriate for academia and policy makers. This definition needs to be comprehensive and uniform, covering quite a wide variety of cases while at the same time guide us towards understanding the phenomenon. A well-developed lexical definition may be the most suitable for this purpose. As an example of this type of definitions the WHO definition can be used. This definition is in line with two important purposes of definitions that were mentioned in the introduction. It can serve as a pointer towards better understanding of elder abuse. It also helps to distinguish elder abuse from other phenomena. It is however does not correspond with third purpose of definitions as the definition used by professionals should be more specific and concrete in order to permit effective prevention and intervention strategies. On the other hand, it is necessary for a definition to be specific and concrete in some settings. It is especially important in (professional care) practice, as the definitions that are used by practitioners and professionals need to be context specific and enable them to work with and clearly identify elder abuse. They need to guide professionals and to help to understand the characteristics of a particular setting. These definitions should be adapted to these settings and include the features of the conditions, be flexible and reflect the empirical reality. Stipulative definitions that are narrow and specific would meet these objectives.

\section{Conclusion}

The problem of defining elder abuse cannot be easily solved, but it is clear that more attention should be paid to it; it is after all the starting point of our practice and research. The question of defining elder abuse remains open. Do we need a common definition of elder abuse or do we need different definitions that can be used in different settings? Considering the overview of definitions that was discussed above it is clear that definitions, especially those of a social problem like elder abuse, are set in a social surrounding. They are not timeless and change with the currents of socio-historical changes that influence the inclusion and exclusion process of what counts as elder abuse. It is the challenge now, however, to take a further step forward in both practice and research of elder abuse. One such step, albeit a very basic one, we propose here: for research purposes a lexical definition such as the WHO definition should be consistently used. As it was shown earlier this type of definition follows the main purposes of definitions: it leads the enquirer towards a clearer understanding of the problem and helps to differentiate it from other phenomena. For professional practice, however more use can be found in a stipulative definition that set boundaries to the phenomenon and fits with the cultural and social context of that practice. Since lexical definitions do not serve this purpose, they are not appropriate for these particular settings. However, we argue that as scholars we can nevertheless set a first step by choosing one lexical definition that we will all follow in our research. Since it is already widely used but not systematically (Comijs et al., 1998; Comijs, 1999; National Research Council, 2003) we propose to follow the WHO definition "elder abuse is a single or repeated act or lack of appropriate action, occurring within any relationship where there is an expectation of trust that causes harm, distress to an older person". One definition might not be enough for the social problem we are dealing with, but it could be a helpful and necessary starting point to enable further understanding of and research on elder abuse.

\section{Conflict of interest}

None declared.

\section{References}

Abbey, L., 2009. Elder abuse and neglect: when home is not safe. Clinics in Geriatric Medicine 25, 47-60.

Anetzberger, G.J., 2004. The reality of elder abuse. Clinical Gerontologist 28, $1-25$.

Ansello, E.F., O'Neill, P., 2010. Abuse, neglect, and exploitation: considerations in aging with lifelong disabilities. Journal of Elder Abuse \& Neglect 22, $105-130$.

Arai, M. 2006. Elder abuse in Japan. Educational Gerontology 32 (1), 13-23.

Baker, A.A., 1975. Granny-battering. Modern Geriatrics 5, 20-24.

Baron, S., Welty, A., 1996. Elder abuse. Journal of Gerontological Social Work 25 (1/2), 33-57.

Belnap, N., 1993. On rigorous definitions. International Journal for Philosophy in the Analytic Tradition 72, 115-146.

Biggs, S., Phillipson, C., Kingston, P., 1995. Elder Abuse in Perspective. Open University Press, London.

Block, M., Sinnott, I., 1979. The Battered Elder Syndrome. University of Maryland Press, Maryland.

Brammer, A., Biggs, S., 1998. Defining elder abuse. Journal of Social Welfare and Family Law 20 (3), 285-304.

Burston, G.R., 1975. Granny battering. British Medical Journal 3, 592.

Burston, G.R., 1977. Do your elderly patients live in fear of being battered? Modern Geriatrics 7, 54-55.

Cloke, C., 1983. Old Age Abuse in a Domestic Setting. Age Concern, London.

Comijs, C.H., 1999. Elder Mistreatment; Prevalence, Risk Indicators and Consequences. Vrije Universiteit, Amsterdam, Proefschrift.

Comijs, H.C., Pot, A.M., Smit, J.H., Jonker, C., 1998. Elder abuse in the community: prevalence and consequences. Journal of the American Geriatrics Society 46 885-888.

Comijs, H.C., Dijkstra, W., Bouter, L.M., Smit, J.H., 2000. The quality of data collection byan interview on the prevalence of elder mistreatment. Journal of Elder Abuse and Neglect 12 (1), 57-72.

Cregan A., 2005. Towards a Science of Definition. Australian Ontology Workshop. Sidney.

Eastman, M., 1982. Granny battering, a hidden problem. Community Care 413, 27.

Eastman, M., 1984. Old Age Abuse. Age Concern England.

Griffin, L.W., 1994. Elder maltreatment among rural African-Americans. Journal of Elder Abuse \& Neglect 6 (1), 1-27

Gulpa, A., 2008. Definitions. The Stanford Encyclopedia of Philosophy. http://plato.stanford.edu/archives/spr2009/entries/definitions/ (accessed 10.02.11)

Harbison, J., Morrow, M., 1998. Questions and contradictions: A re-examination of the social construction of elder abuse and neglect. Ageing and Society 18 , $691-711$.

Ierodiakonou, K., 1993. The stoic division of philosophy. A Journal for Ancient Philosophy 38 (1), 57-74.

Kivela, S., Kongas-Saviaro, P., Kesti, E., Pahkala, K., Ijas, M., 1992. Abuse in old age epidemiological data from Finland. Journal of Elder Abuse \& Neglect 4 (3), 1-18.

McCreadie, C., 1993. From granny battering to elder abuse: a critique of U.K. writing 1975-1992. Journal of Elder Abuse and Neglect 5 (2), 7-24.

McCreadie, C., 1996. Elder Abuse: Update on Research. Age Concern and Institute of Gerontology, London.

McCreadie, C., 2003. The nature of elder abuse. In: Amiel, S., Heath, I. (Eds.), Family Violence in Primary Care. Oxford University Press, Oxford.

McMullen, J.E., 2004. Bushed Neglect of Seniors in British Columbia: Theoretical Analysis. Saint Mary's University.

National Research Council, 2003. Elder mistreatment. Abuse, neglect, and exploitation in an aging America. Panel to review risk and prevalence of elder abuse and neglect. In: Bonnie, R.J., Wallace, R.B. (Eds.), Committee on National Statistics and Committee on Law and Justice, Division of Behavioral and Social Sciences and Education. The National Academies Press, Washington, DC.

Newton, J.P., 2010. Elder abuse - an issue not to be ignored. Gerontology 27, 83.

Ogg, J., Bennett, G., 1992. Elder abuse in Britain. British Medical Journal 305 998-999.

O‘Malley, H., Sgel, H., Perez, R., 1979. Elder Abuse in Massachusetts. Legal Research and Services to the Elderly, Boston.

Perel-Levin, S., 2008. Discussing Screening for Elder Abuse at Primary Health Care Level. WHO.

Pillemer, K.A., Wolf, R.S., 1986. Elder Abuse: Conflict in the Family. Auburn House Publishing Company, Dover, MA.

Pillemer, K., Finkelhor, D., 1988. The prevalence of elder abuse: a random sample survey. The Gerontologist 28, 51-57.

Pillemer, K., Prescott, D., 1989. Psychological effects of elder abuse: a research note. Journal of Elder Abuse \& Neglect 1, 65-74. 
Podnieks, E., 1992. National survey on abuse of the elderly in Canada. Journal of Elder Abuse \& Neglect 4 (1/2), 5-58.

Pritchard, J., 1995. The Abuse of Older People, 2nd ed. Jessica Kingsley Publishers, London.

Schlesinger, R.A., 1984. Granny bashing: an introduction to the problem. Canadian Women Studies 5, 57-59.

Thane, P., 1978. The muddled history of retiring at 60 and 65 . New Society 45 (826), 234-236.
World Health Organization, 2002. Active Ageing: A Policy Framework. Geneva.

World Health Organization, 2011. Definition of An Older or Elderly Person. http://www.who.int/healthinfo/survey/ageingdefnolder/en/index.html (accessed 10.02.11).

Zalta, E., Nodelman, U., Allen, C., Perry, J., 2009. Stanford Encyclopedia of Philosophy. Definitions. http://plato.stanford.edu/archives/spr2009/entries/definitions/ (accessed 10.12.10). 